\title{
Associations of Parental Influences with Physical Activity and Screen Time among Young Children: A Systematic Review
}

\author{
Huilan Xu, ${ }^{1,2}$ Li Ming Wen, ${ }^{1,2,3}$ and Chris Rissel ${ }^{1}$ \\ ${ }^{1}$ Sydney School of Public Health, University of Sydney, Sydney, NSW 2006, Australia \\ ${ }^{2}$ Health Promotion Service, Sydney Local Health District, Level 9, King George V Building, Missenden Road, \\ Camperdown, NSW 2050, Australia \\ ${ }^{3}$ Shanghai 10th People's Hospital, University of Tongji, Shanghai, China
}

Correspondence should be addressed to Huilan Xu; huilan.xu@sswahs.nsw.gov.au

Received 28 July 2014; Revised 14 November 2014; Accepted 24 November 2014

Academic Editor: Gengsheng He

Copyright (C) 2015 Huilan Xu et al. This is an open access article distributed under the Creative Commons Attribution License, which permits unrestricted use, distribution, and reproduction in any medium, provided the original work is properly cited.

\begin{abstract}
Parents play a critical role in developing and shaping their children's physical activity (PA) and sedentary behaviours, particularly in the early years of life. The aim of this systematic review is to identify current literature investigating associations of parental influences with both PA and screen time in young children. This systematic review was conducted in November 2013 using 6 electronic databases covering research literature from January 1998 to November 2013. Thirty articles that met inclusion criteria were identified. These studies covered five important aspects of parenting: (1) parenting practices; (2) parents' role modelling; (3) parental perceptions of children's PA and screen viewing behaviours; (4) parental self-efficacy; and (5) general parenting style. Findings suggest that parents' encouragement and support can increase children's PA, and reducing parents' own screen time can lead to decreased child screen time. Improving parenting practices, parental self-efficacy or changing parenting style may also be promising approaches to increasing PA time and decreasing screen time of young children.
\end{abstract}

\section{Introduction}

Physical activity (PA) and sedentary behaviours (predominantly screen time) impact on the weight status of children [1-3]. Research evidence suggests that helping young children establish an active lifestyle can prevent them from overweight and obesity [4-7]. In the early years of life, parents play a critical role in developing and shaping their children's PA and sedentary behaviours through role modelling and creating a healthy home environment that increases PA and reduces screen time [8].

There have been several systematic reviews investigating correlates of PA and sedentary behaviours in young children [9-13]. These reviews used a social-ecologic framework [14] to summarize the correlates of PA and screen time of young children in five domains: (1) demographic and biological; (2) psychological, cognitive, and emotional; (3) behavioural attributes and skills; (4) social and cultural; and (5) physical environmental. Although parents' role modelling, parenting practices and parental perceptions of children's PA, and sedentary behaviours are part of the social and cultural domain, they have not been explicitly discussed in these reviews. General parenting style and parental self-efficacy that are also part of the social and cultural domain have not been investigated in these reviews.

In addition to parents' role modelling and parenting practices, general parenting style and parental self-efficacy also influence the development of PA and sedentary behaviours of young children, particularly in the early years of life [8]. Parenting style refers to a general pattern of parenting that provides the emotional background in which parents' behaviours are expressed and interpreted by a child [8]. It can be conceptualized as a context that moderates the influence of specific parenting practices on a child. Closely related to parenting practices and parenting style, parental self-efficacy is regarded as a parent's belief that he or she is capable of organizing and executing tasks related to parenting a child [15].

Findings from a recent systematic review [16] investigating associations between parental factors (parents' role 
modelling, parenting practices, and parental perceptions of importance and value of PA) and young children's PA were inconsistent, reporting that parental and family dynamics associated with children's PA are undeveloped. In particular, the review did not examine the parental influences on children's screen time (the time spent on watching TV, DVDs, or videos, using a computer and playing with an electronic game system) despite increasing research interest in investigating children's screen time and its independent association with childhood obesity. Further investigation was called for to clarify and understand specific parental influences that are associated with PA in children using comprehensive reviews of well-defined parental influences and their effects on both $\mathrm{PA}$ and screen time.

To fill in the knowledge gaps in this area, we aimed to update the current literature investigating parental influences and their associations with both PA and screen time in young children.

\section{Methods}

2.1. Search Strategy. In November 2013, a systematic search of the literature was conducted. Literature included in this review was retrieved from six electronic databases, including Medline, the Cochrane Central Register of Controlled Trials (CENTRAL), Cochrane Database for Systematic Review (CDSR), PsycINFO, EMBASE, and Web of knowledge. Research papers were limited to those written in English and published or included in databases from 1998 to November 2013. There was no restriction of study designs. Study participants in searched papers were limited to parents, father, and/or mother with young children aged $\leq 6$ years. Parental influences included (1) parenting practices, (2) parents' role modelling (parents' own PA and screen time), (3) parental perceptions of children's PA and screen viewing behaviours, (4) parental self-efficacy, and (5) general parenting style. Children's PA included parent-reported "outdoor play" or "active play" and objectively measured PA level (e.g., accelerometer). The search strategy used for the Medline database is displayed in Table 1. A similar search strategy was used for other databases. Additional manual searches of the references of selected articles were also conducted for other relevant articles. Grey literature, such as unpublished studies and dissertations, was also included.

2.2. Study Selection. Study selection was based on predefined inclusion and exclusion criteria. The inclusion criteria were (1) individual quantitative studies that examined relationships of parental influences (covering at least one of the five aspects) with PA or screen time of young children; (2) studies with children aged $\leq 6$ years old, or studies with a wide age range but describing the results specifically for children aged $\leq 6$ years old; and (3) full text articles or dissertations, written in English. Studies were excluded from this review, if they were (1) pilot studies, (2) validation studies, (3) qualitative studies, (4) review papers, (5) studies that examined correlates of children's PA or screen time but did
TABLE 1: The search strategy used for Medline database.

Database: Ovid Medline(R) 〈1946 to November Week 3 2013〉 search strategy:

(1) preschool*.mp. (763123)

(2) young child*.mp. (34520)

(3) early child*.mp. (15721)

(4) toddler.mp. (1946)

(5) (1) or (2) or (3) or (4) (783324)

(6) parenting style ${ }^{*} . \mathrm{mp}$. (762)

(7) parenting practice.mp. (26)

(8) parenting behavio*.mp. (847)

(9) parenting.mp. (14946)

(10) maternal influence ${ }^{*} . m p$. (460)

(11) parental influence ${ }^{*}$.mp. (439)

(12) parental self-efficacy.mp. (79)

(13) parental confidence.mp. (51)

(14) parental rules.mp. (61)

(15) parental attitudes.mp. (730)

(16) parental concerns.mp. (324)

(17) parent* ${ }^{*}$ support*.mp. (1197)

(18) parent ${ }^{*}$ encouragement.mp. (80)

(19) parent* involvement.mp. (1051)

(20) parent modeling.mp. (22)

(21) (6) or (7) or (8) or (9) or (10) or (11) or (12) or (13) or (14) or

(15) or (16) or (17) or (18) or (19) or (20) (18529)

(22) physical activit ${ }^{*} . \mathrm{mp}$. (55070)

(23) total PA.mp. (264)

(24) MVPA.mp. (1001)

(25) PA.mp. (54822)

(26) VPA.mp. (3623)

(27) physical exercise.mp. (9183)

(28) outdoor play.mp. (102)

(29) active play.mp. (87)

(30) play.mp. (449998)

(31) leisure activit*.mp. (7741)

(32) (22) or (23) or (24) or (25) or (26) or (27) or (28) or (29) or

(30) or (31) (569321)

(33) physical inactivity.mp. (3827)

(34) sedentary behavio*.mp. (1660)

(35) television viewing.mp. (957)

(36) TV viewing time.mp. (96)

(37) TV viewing.mp. (503)

(38) TV time.mp. (71)

(39) DVD*.mp. (951)

(40) video viewing.mp. (83)

(41) computer using.mp. (512)

(42) computer time.mp. (255)

(43) electronic game.mp. (34)

(44) screen time.mp. (449) 
TABLE 1: Continued.

Database: Ovid Medline(R) 〈1946 to November Week 3 2013〉

search strategy:

(45) small-screen recreation.mp. (15)

(46) (33) or (34) or (35) or (36) or (37) or (38) or (39) or (40) or

(41) or (42) or (43) or (44) or (45) (8478)

(47) (32) or (46) (573869)

(48) (5) and (21) and (47) (553)

(49) limit (48) to (English language and humans and $\mathrm{yr}=$ "1998-current") (483)

${ }^{*}$ The asterisk sign stands for any character(s).

not include any aspects of defined parental influences for this review, and (6) studies involving children aged $>6$ years.

A total of 1414 articles were identified through database searching. Duplicate articles $(n=307)$ were removed, resulting in 1107 individual articles for consideration. By screening the titles, 1062 articles were considered to be irrelevant and thus excluded. Forty-five papers including grey literature remained as a result of the initial search. The references of these remaining 45 articles were further screened manually to identify other relevant articles. Five additional articles were included. A total of 50 full texts were further assessed. After excluding 20 articles according to the criteria, 30 articles were included in the present review. The process of study selection is reported in Figure 1.

2.3. Assessment of Included Articles. Two reviewers (Huilan $\mathrm{Xu}$ and Li Ming Wen) independently screened the study titles and abstracts and then critically appraised the selected articles. Due to heterogeneity of these studies (i.e., differences in study design, study quality, and statistical analysis method), it was not possible to conduct a meta-analysis that uses statistical methods to summarize the results. Therefore, the results from this review are presented descriptively. We critically evaluated the papers using a previously established quality checklist [17] with some modifications. This quality assessment tool was originally adapted from the Strengthening the Reporting of Observational Studies in Epidemiology (STROBE) statement [18]. For this review, the quality checklist consists of eight query items as follows: (1) was the study longitudinal or randomised controlled trail (RCT)? (2) Did the study describe the participant eligibility criteria? (3) Were the study participants randomly selected (or representative of the study population)? (4) Did the study report the sources and details of assessment for parental influences and did the instruments have acceptable reliability? (5) Did the study report the sources and details of assessments for PA and screen time and did all the methods have acceptable reliability for specific age group? (6) Did the study report a power calculation and was the study adequately powered to detect hypothesized relationships? (7) Did the study report the numbers of individuals who completed each of the different measures and did participants complete at least $80 \%$ of measures? (8) Did statistical analysis take into account the confounding? A score of "1" was assigned to "yes" to the query

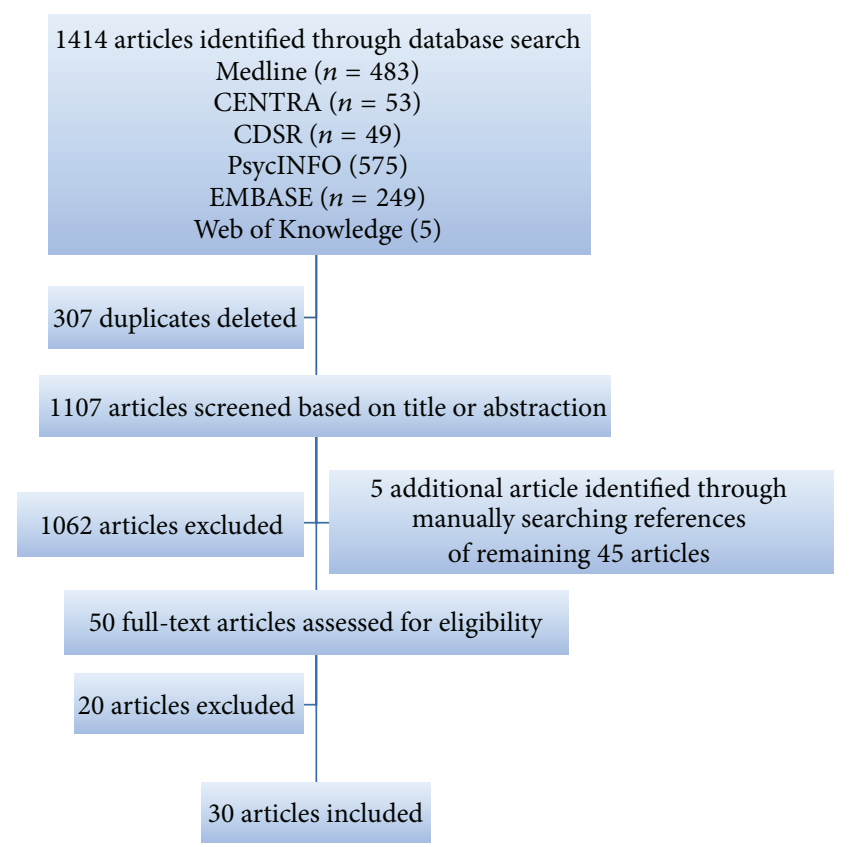

FIGURE 1: Flow diagram of study selection.

item, or a score of " 0 " was assigned. The range of score was from " 0 " to " 8 " for each paper. A paper with a score above 5 was regarded as a good quality paper.

\section{Results}

3.1. Description of Studies. Of the 30 articles included in this review, 14 studies were conducted in the United States, 6 in Australia, three in Canada, two in New Zealand, and one in each of Turkey, Greece, or Netherlands (Tables 2, 3, and 4). Fourteen studies [19-32] (Table 2) examined the association between parental influences and PA, with 12 studies [3344] (Table 3) examined the association between parental influences and screen time, and four studies [45-48] (Table 4) examined associations of parental influences with both PA and screen time.

The quality scores of the papers ranged from 2 to 7 with an average score of 4.9. Most studies $(n=24)$ used cross-sectional design, with only 6 longitudinal studies having follow-up duration from 1 to 5 years. Sample sizes of these studies were reasonable based on their effect size and significance level except two studies had less than 100 participants.

\subsection{Aspects and Measurement of the Parental Influences}

3.2.1. Parenting Practices. The review found that various components of parenting practices regarding PA [20-23, 25$29,31,45,46]$ or screen time [33-35, 38, 43, 45, 46, 48] were reported by 20 included studies. For child PA, parenting practices included (1) parents encouragement or support (e.g., parents participated in PA with their child, provided transportation to PA facilities, watched the child in activities, 


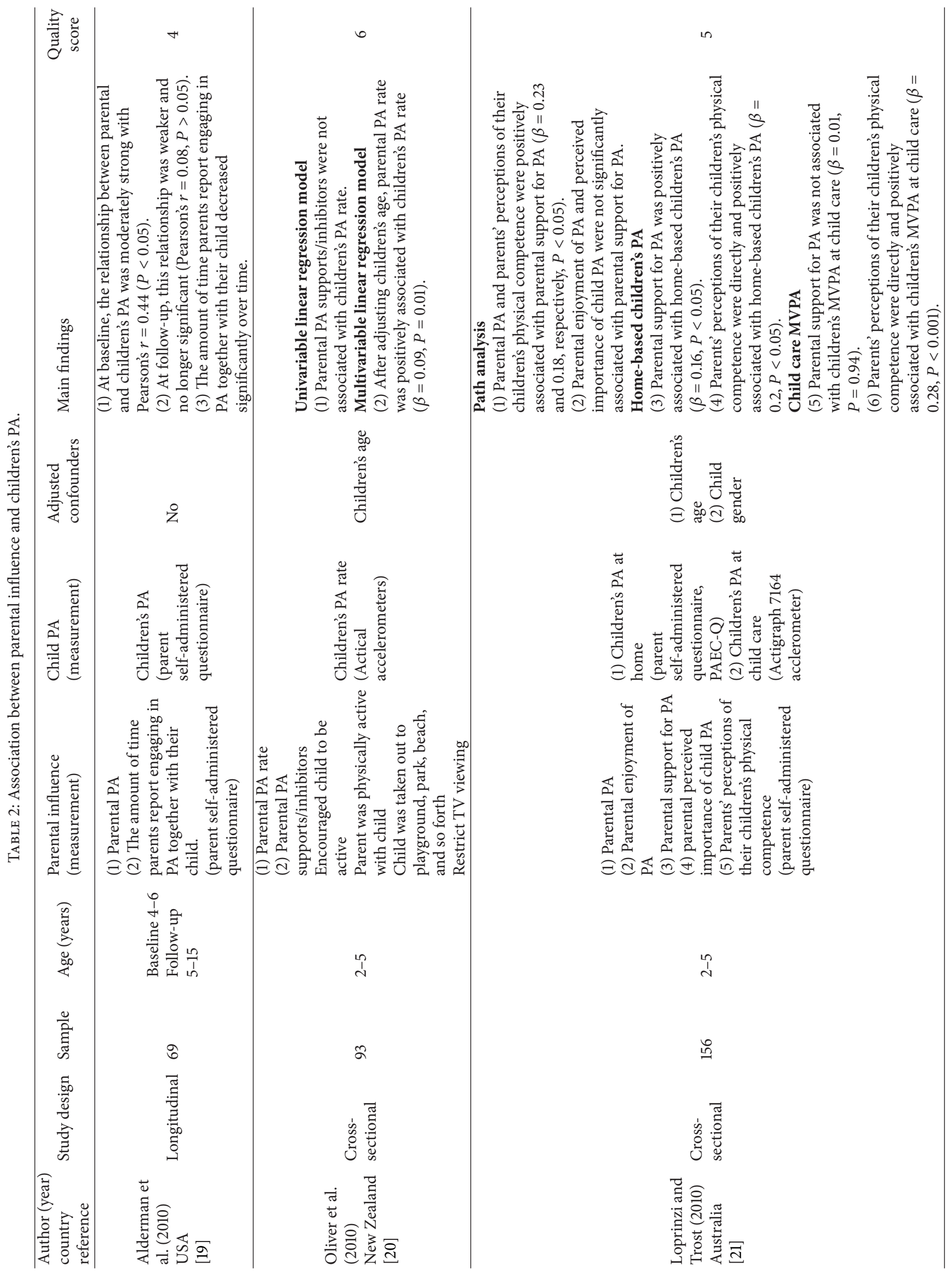




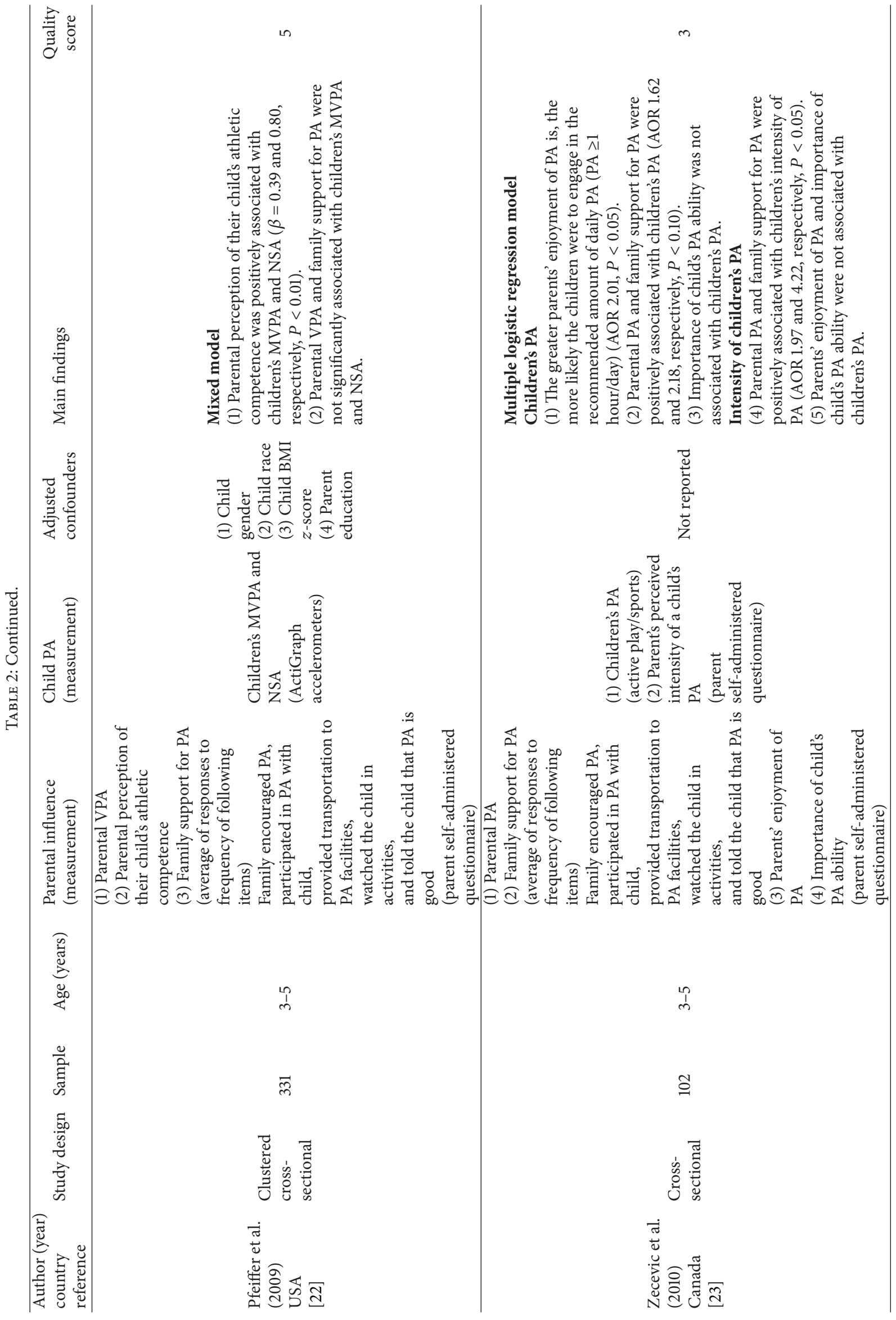




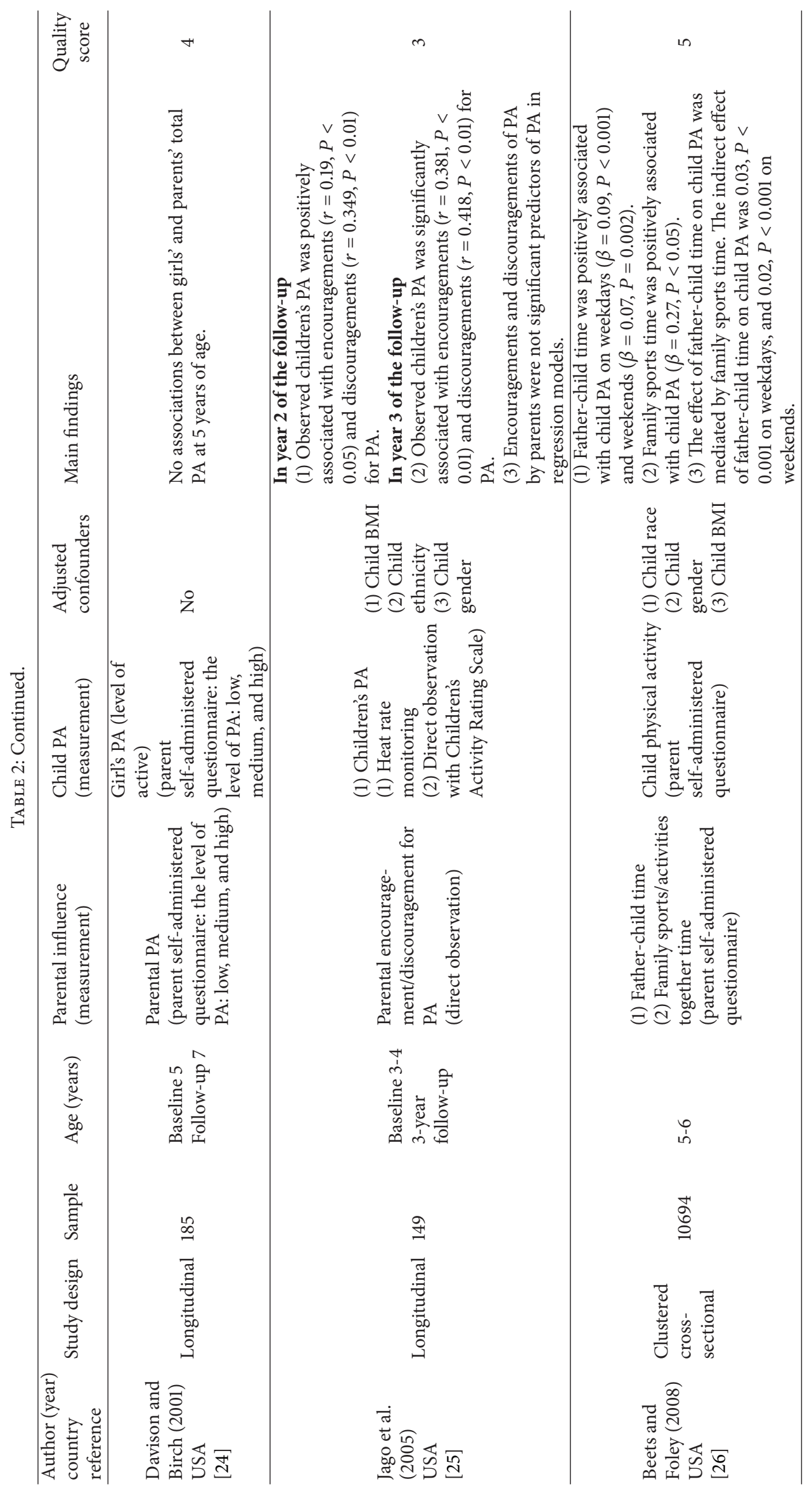




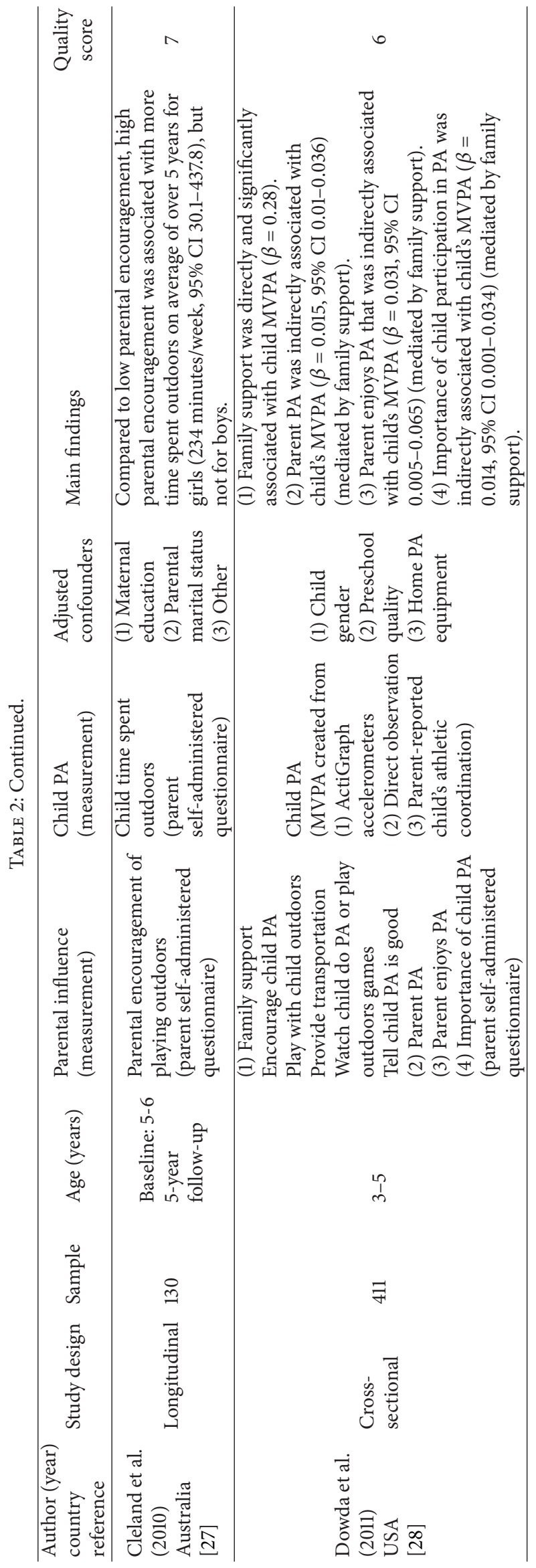




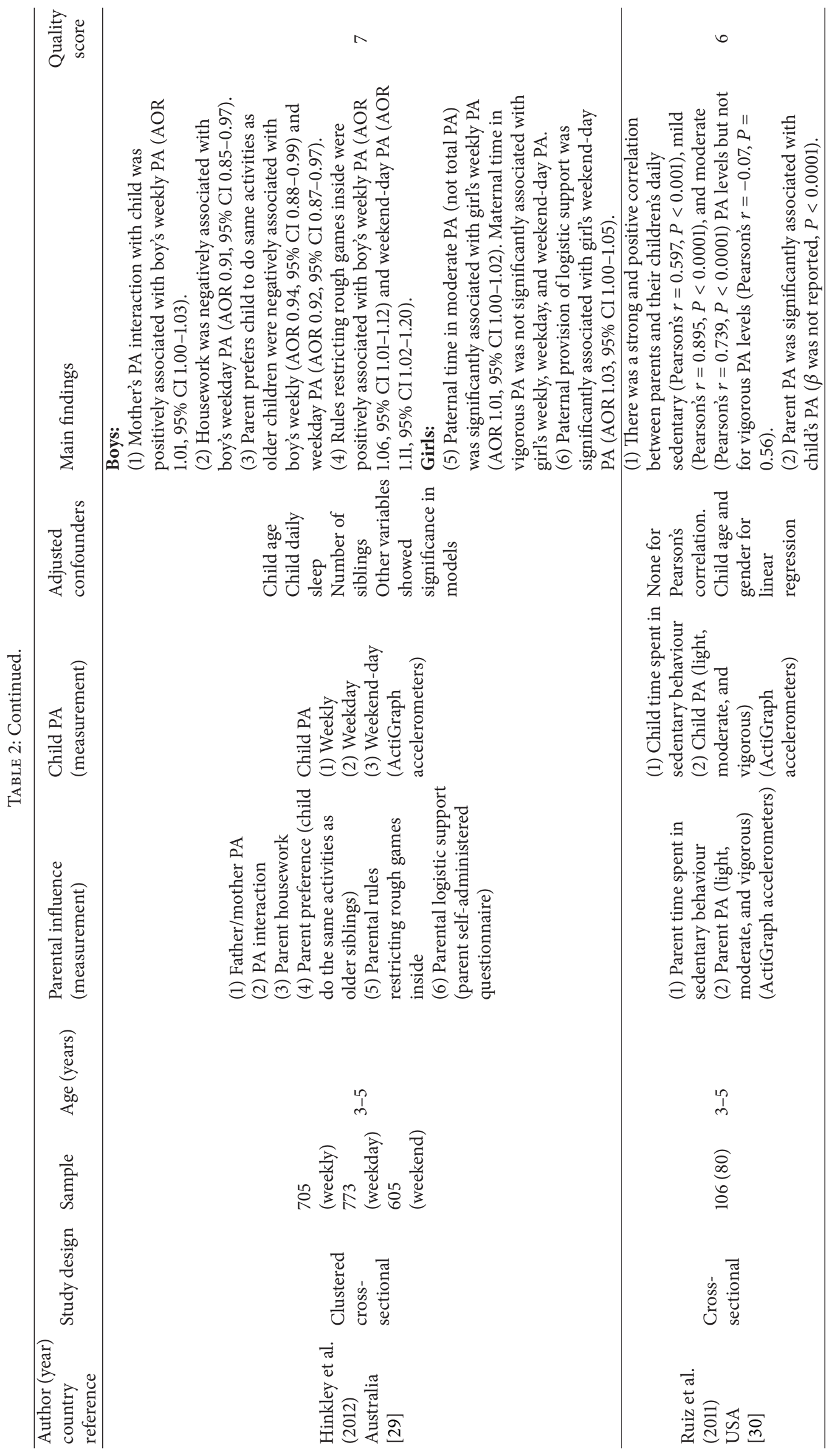




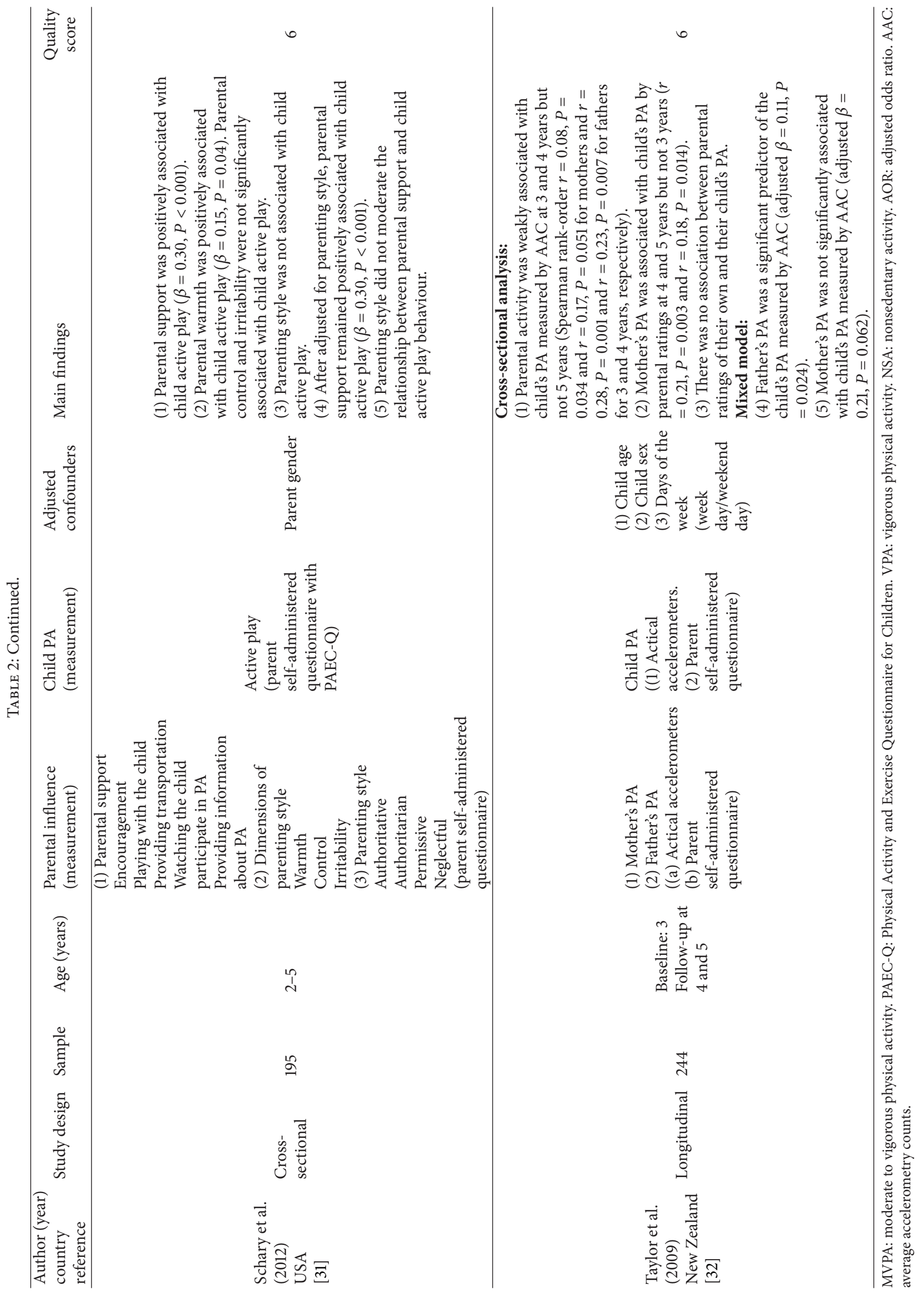




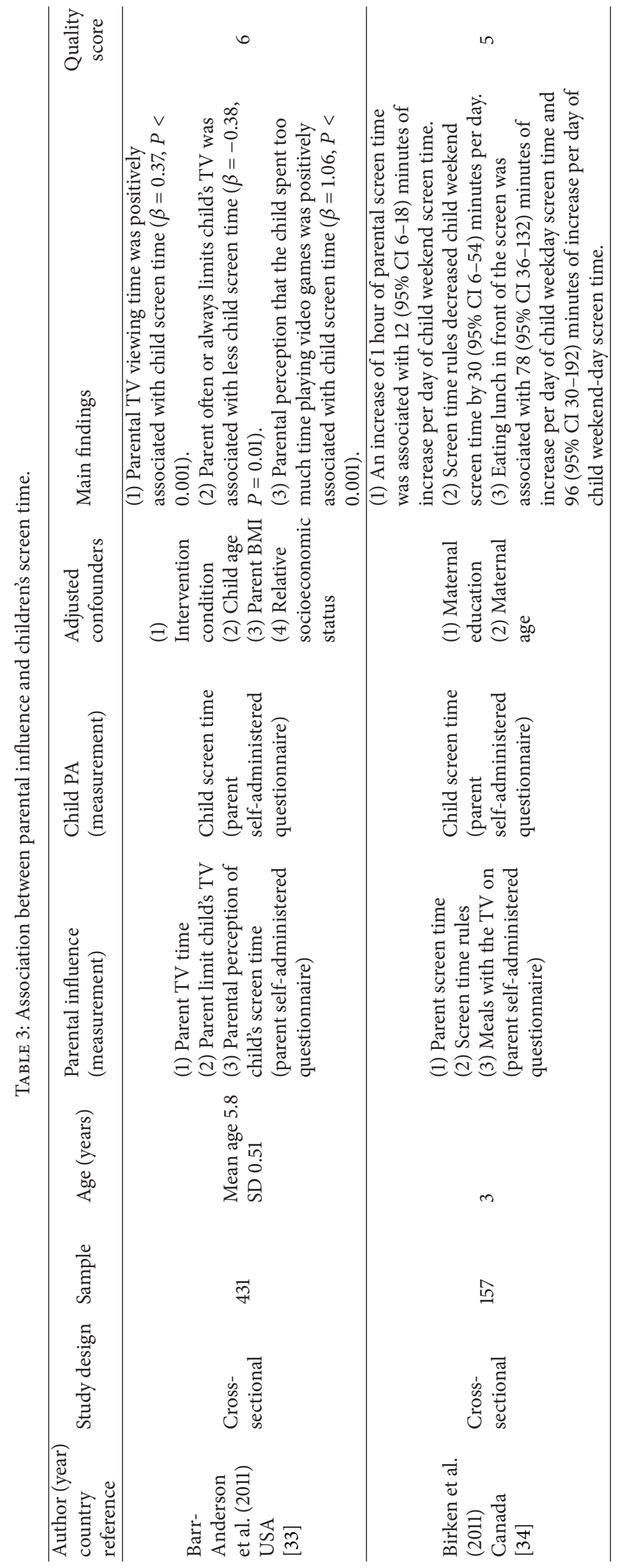




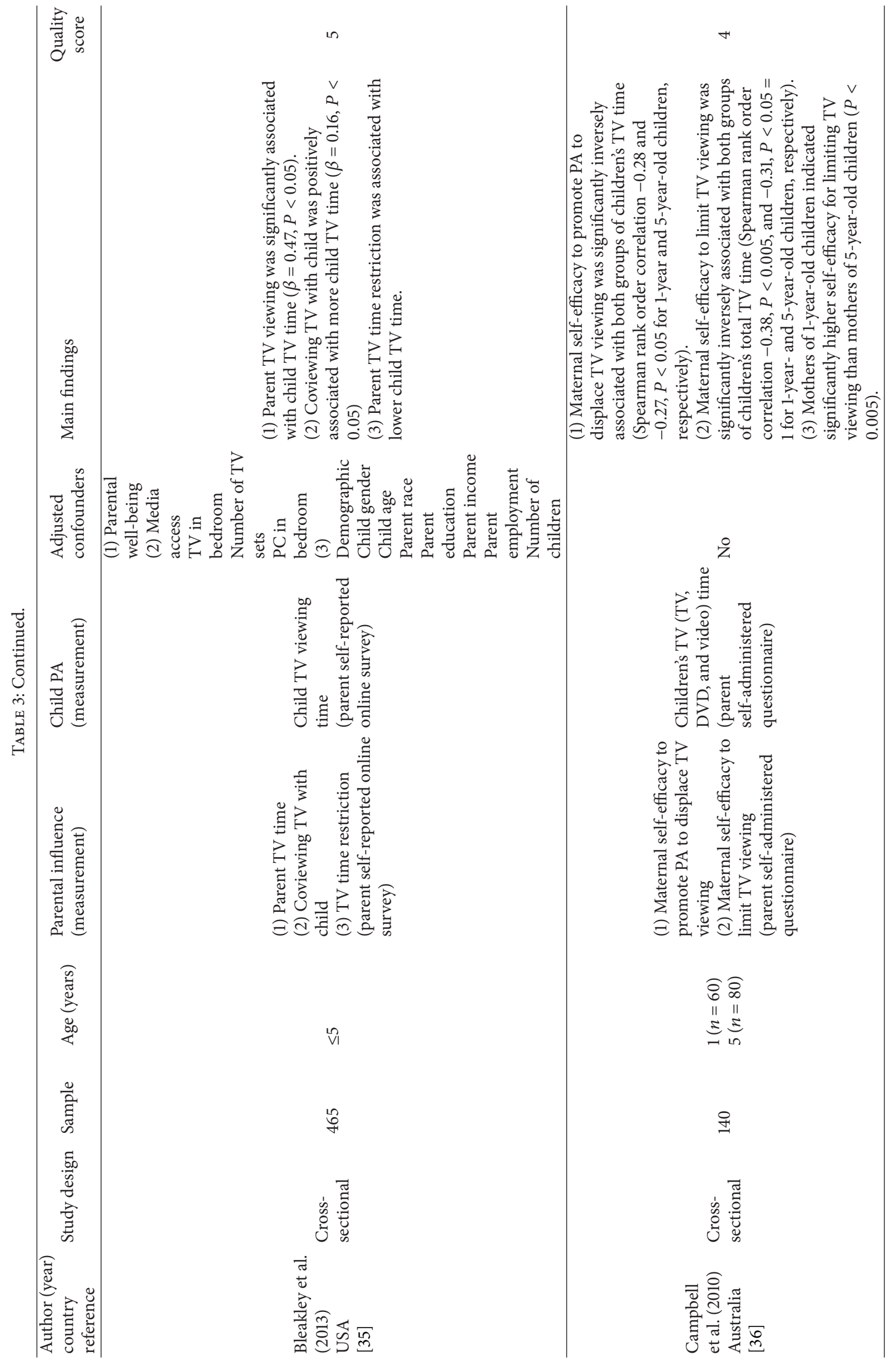




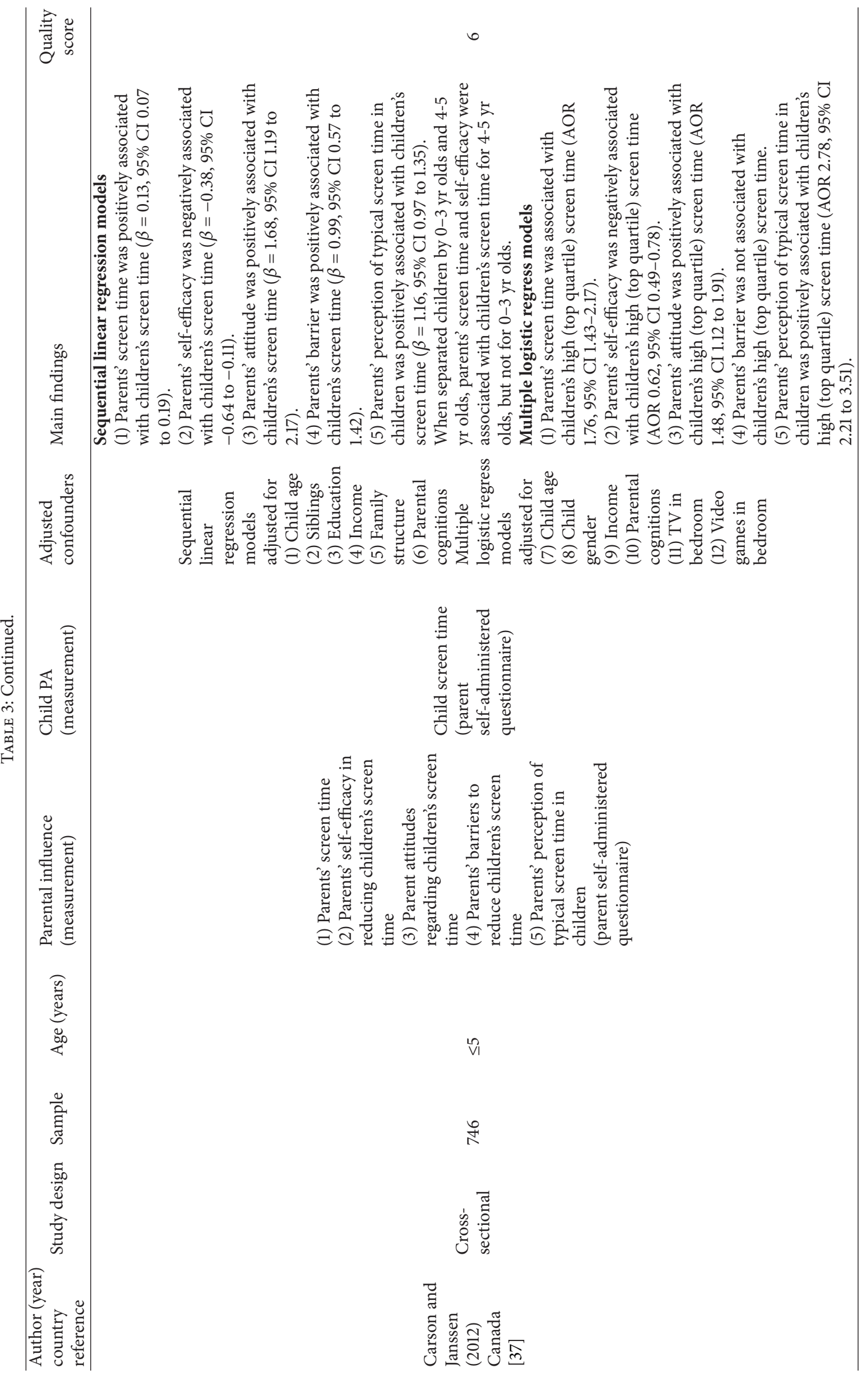




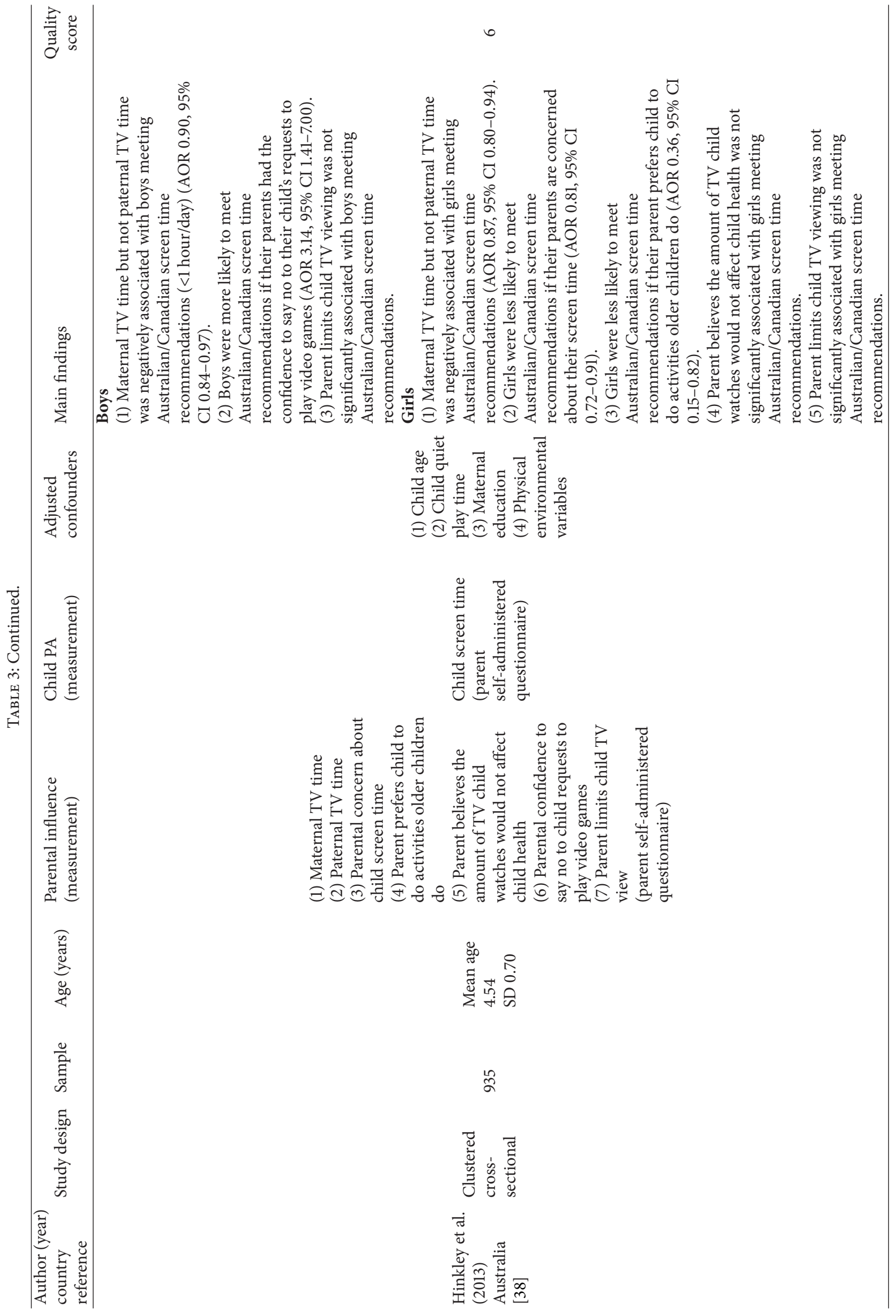




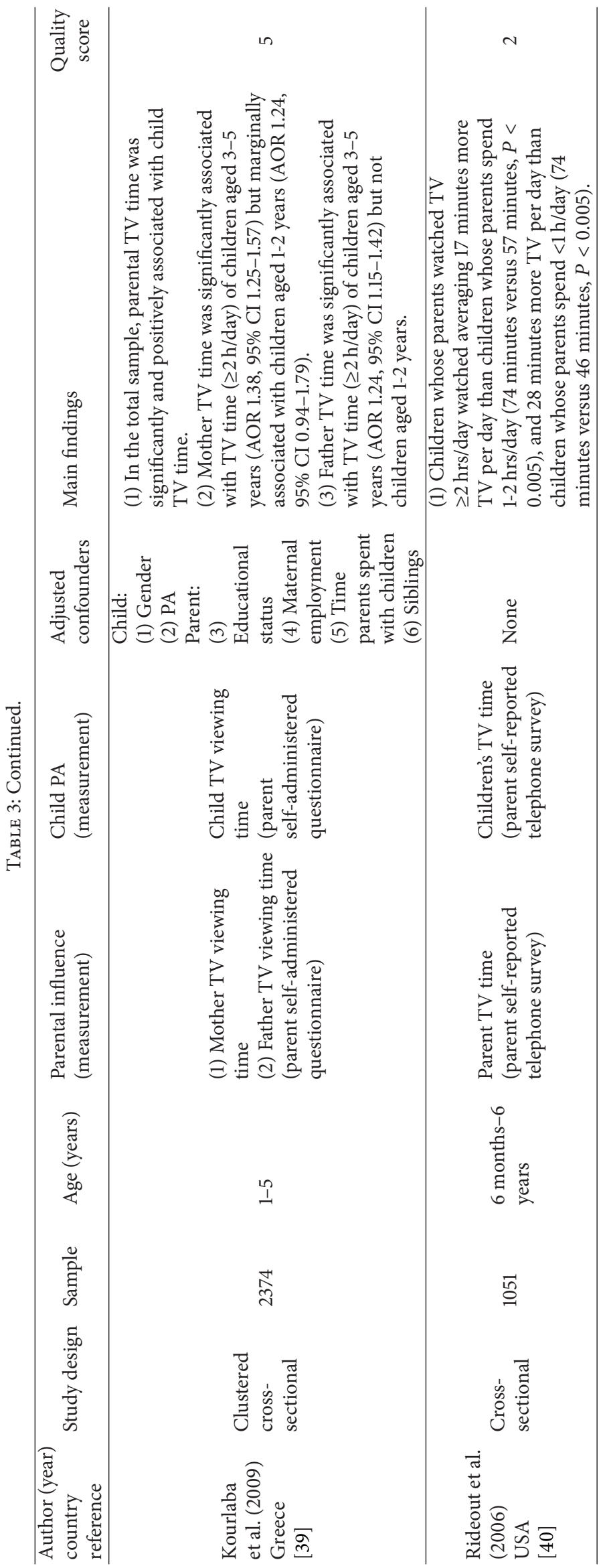




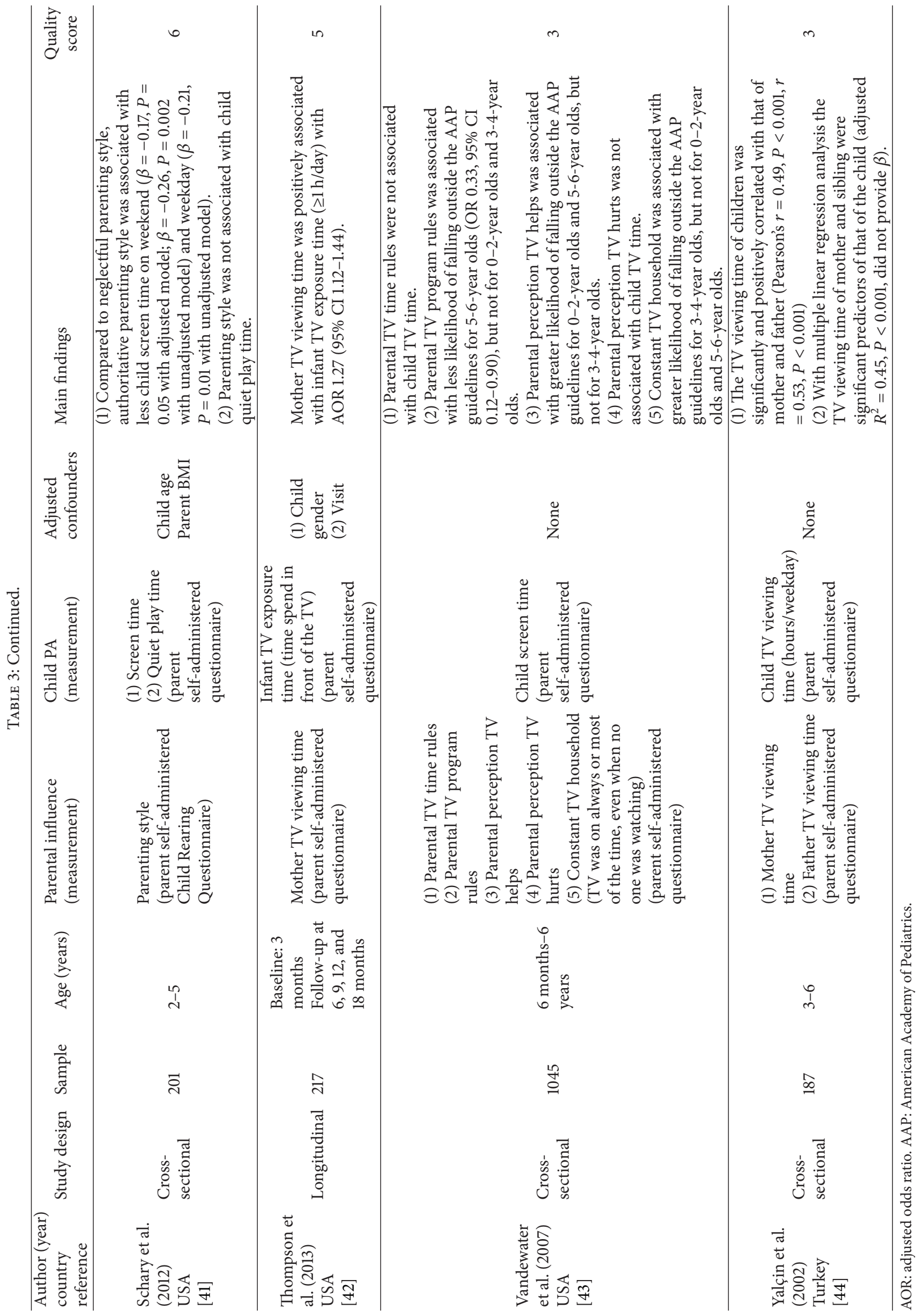




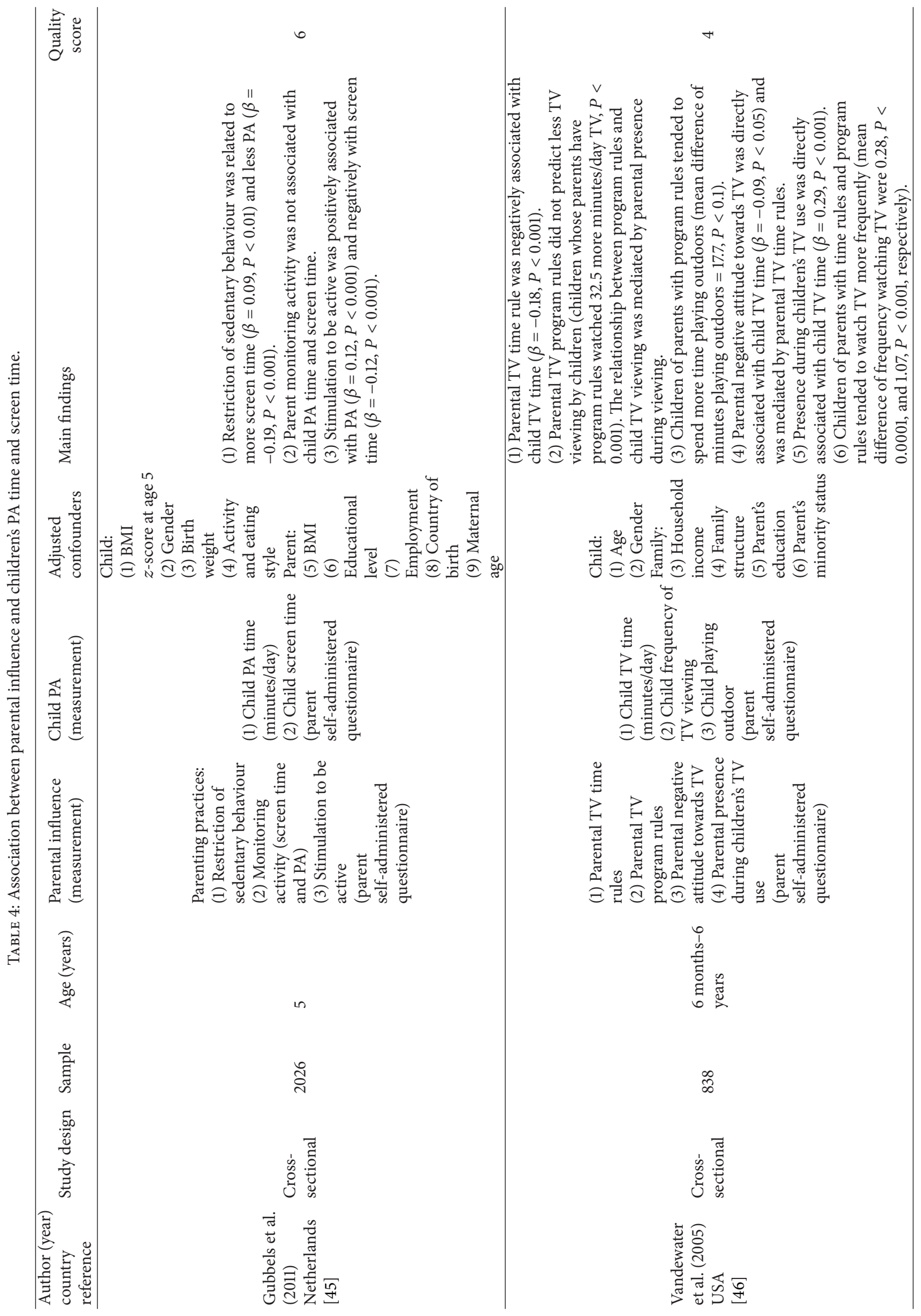




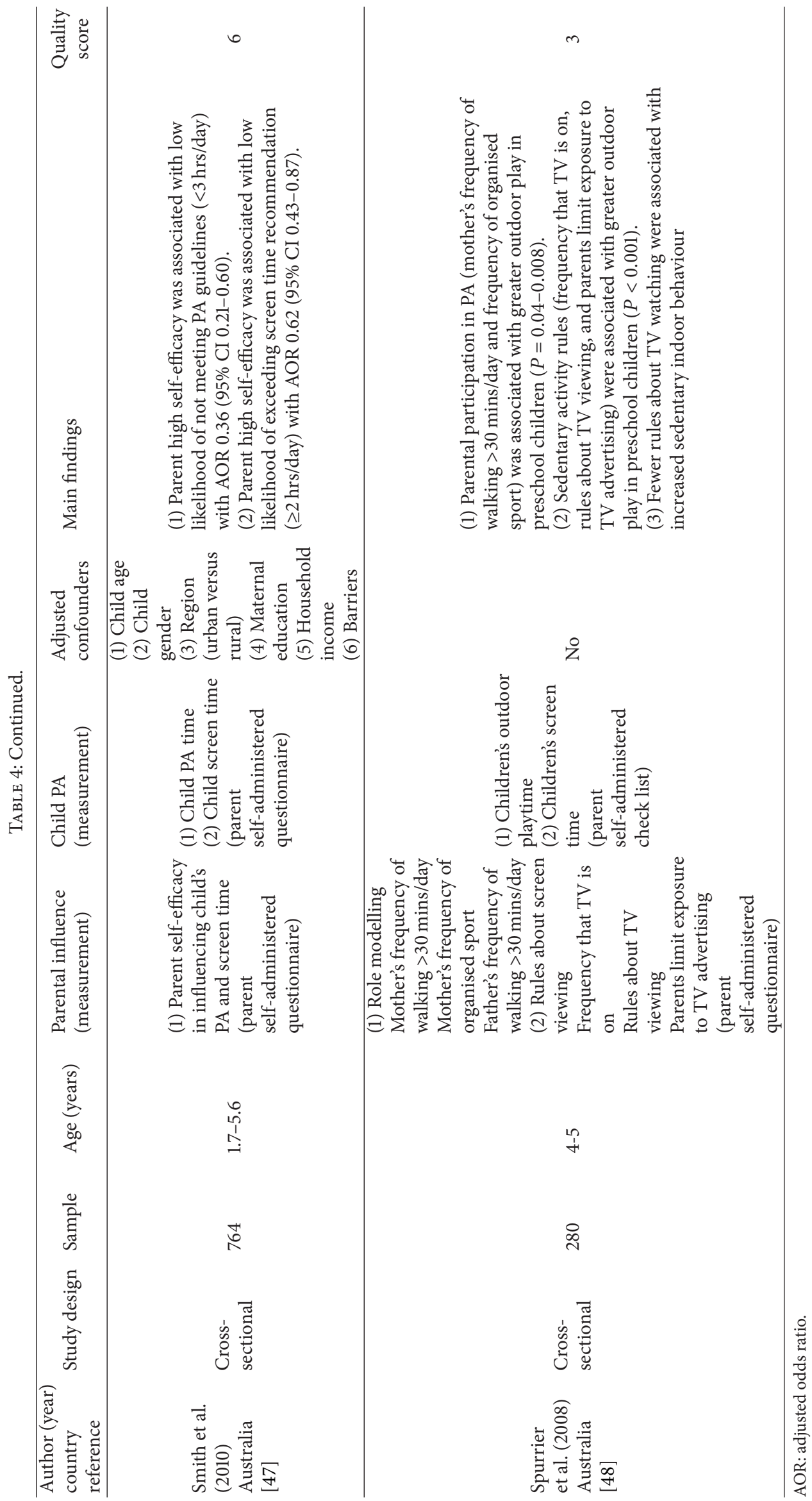


TABLE 5: Papers reporting an association between parental influences and children's PA.

\begin{tabular}{|c|c|c|c|}
\hline \multirow{2}{*}{ Parental influences } & \multicolumn{3}{|c|}{ Association with children's physical activity } \\
\hline & Positive & Negative & No association \\
\hline \multicolumn{4}{|l|}{ Parenting practices } \\
\hline (1) Parents encourage/support PA & $20,21,23,24,26,30,32,45$ & & $25,27,28$ \\
\hline \multicolumn{4}{|l|}{ (2) Parental rules } \\
\hline Restricting rough games inside & 24 & & \\
\hline TV viewing rules & 47,48 & 45 & \\
\hline $\begin{array}{l}\text { (3) Parent preference } \\
\text { (child do the same activities as older siblings) }\end{array}$ & & 24 & \\
\hline Parent role modelling (parents' $P A$ ) & $19,23,24,27,29,31,32,47$ & & 22,28 \\
\hline \multicolumn{4}{|l|}{ Parent perception } \\
\hline (1) Parent perception of importance of child PA & 23 & & 32 \\
\hline (2) Parent perceptions of children's physical competence & 26,28 & & \\
\hline Parental self-efficacy in PA & 46 & & \\
\hline Parenting style & & & 30 \\
\hline Dimensions of parenting style (warmth) & 30 & & \\
\hline
\end{tabular}

or let their child know that PA is good for health); (2) setting rules (e.g., restricting indoor games and having TV viewing rules); (3) parents preference (e.g., preferring child to do the same activities with their older siblings). For children's screen time, parenting practices included (1) setting TV rules (e.g., time or program rules); (2) watching TV with their child; (3) monitoring screen time; (4) having meals without watching TV; and (5) stimulating children to be active.

3.2.2. Parents' Role Modelling (Parents' Own PA and TV/Screen Time). Eight studies [19, 21-24, 28, 29, 48] used parent self-administered questionnaires to assess parents' own PA time, frequency, and intensity with two studies using accelerometer $[20,30]$ and one study using both parent self-administered questionnaire and accelerometer [32]. Nine studies used a questionnaire to measure parental TV time [33-35, 37-40, 42, 44]. Of them, two studies measured screen time rather than TV time $[34,37]$.

3.2.3. Parental Perceptions. Perception of importance of children's PA [23, 28] and perception of children's physical competence $[21,22]$ were reported in 4 studies. In examining children's screen time, perception of "too much screen time" $[33,38]$, “TV helps children's learning” $[37,43]$, or “TV hurts children's learning" $[43,46]$ were reported in five studies.

3.2.4. Parenting Self-Efficacy. Parental self-efficacy for limiting screen time was assessed by a single item: the level of confidence that parent could say "No" to their child's request for screen time (TV/computer/video games) [36-38]. One study assessed parental self-efficacy for influencing their child's PA in eight challenging situations such that the parent cannot think of activities to suggest; the parent is not able to participate in the activity [47].
3.2.5. Parenting Style. Only one study investigated the association of general parenting style and children's PA [31]. Parenting style was classified by using Maccoby and Martin's [49] classifications of parenting style with two dimensions responsiveness (parental warmth/hostility) and demandingness (parental control).

3.3. Classification and Measurement of Children's $P A$ and Screen Time. Children's PA was measured by parent selfadministered questionnaire in 10 studies $[19,23,24,26,27$, $31,45-48]$, followed by accelerometer in 7 studies [20-22, 28$30,32]$, or heart rate monitoring and direct observation in one study [25].

Screen time was assessed by totaling the time spent on TV, DVDs, electronic game, and computer ( $n=16$ studies), which was always measured by parent self-administered questionnaire.

3.4. Parental Influences and Young Children's PA. Table 5 summarized the associations between parental influences and children's PA. Through examining three aspects of parenting practices on children's $\mathrm{PA}$, there was moderate to strong evidence of linkage between parental encouragement/support and children's PA. For example, of 11 studies examining the relationship between parents' encouragement/support and children's PA, eight studies [21, 23, 26$29,31,45]$ with a mean quality score of 5.6 found that children whose parents encouraged or supported them to do PA were more likely to have higher levels of PA, yet three studies (with a mean quality score of 4.7) did not find such association $[20,22,25]$. The associations of setting rules and parental preference with children's PA were weak due to a small number of studies and inconsistent findings. One study (a quality score of 7) examining both setting PA 
TABLE 6: Papers reporting an association between parental influences and children's screen time.

\begin{tabular}{|c|c|c|c|}
\hline \multirow{2}{*}{ Parent influences } & \multicolumn{3}{|c|}{ Association with children's screen time } \\
\hline & Positive & Negative & No association \\
\hline \multicolumn{4}{|l|}{ Parenting practices } \\
\hline (1) Setting TV rules & & 47 & \\
\hline TV time rules & 45 & $33,34,35,48$ & 38,43 \\
\hline TV program rules & 48 & 43 & \\
\hline (2) Coviewing TV with child & 35,48 & & \\
\hline (3) Monitoring child screen time & & & 45 \\
\hline (4) Meals with TV on & 34,43 & & \\
\hline (5) Stimulation to be active & & 45 & \\
\hline Parent role modelling (Parent screen time) & $33,34,35,37,38,39,40,42,44$ & & \\
\hline \multicolumn{4}{|l|}{ Parent perception } \\
\hline (1) Perception that children spend too much screen time & 33,38 & & \\
\hline (2) Parent perception TV helps & 37,43 & & \\
\hline (3) Parent perception TV hurts & & 48 & 43 \\
\hline Parental self-efficacy in reducing child screen time & & $36,37,38,46$ & \\
\hline Parenting style (authoritative) & & 41 & \\
\hline
\end{tabular}

rules and parent preference found that parental rules were positively associated with boy's PA, but parent preference was negatively associated with boy's PA [29]. Among three studies examining the association between setting TV viewing rules and children's PA, two studies (a mean quality score of 3.5) found that children with TV viewing rules spent more time playing outdoors $[46,48]$, which was not supported by Gubbels et al's study [45].

There was also moderate to strong evidence of positive association between parental PA level and young children's level of activity. Eight studies with a mean quality score of 5.1 found that parents' own PA level was positively associated with young children's PA $[19,20,23,28-30,32,48]$ with only two studies revealing no such association $[22,24]$.

Weak evidence was found in examining associations of parental perception, parental self-efficacy, and parenting style with children's PA due to limited studies and mixed findings. For example, contradictive findings were reported on parental perception of the importance of PA and children's PA in two studies $[23,28]$. But another two studies found that parent perception of children's physical competence was positively associated with children's PA (MVPA) [21, 22]. Only one study found that parents who have a high sense of self-efficacy are more likely to have their children meeting the PA guidelines [47]. General parenting style was not found to be associated with child PA. However, parental warmth, one of the parenting style dimensions, was positively associated with child PA [31].

\subsection{Parental Influences and Young Children's Screen Time.} Table 6 summarized the associations between parental influences and children's screen time. Weak and mixed evidence was found in examining association between parenting practices and screen time. Of 7 studies examining TV time rules, four studies (a mean quality score of 5) found that setting TV time rules resulted in less screen time $[33-35,46]$ and two studies (a mean quality score of 4.5 ) found no such association $[38,43]$ with another study suggesting a negative effect of TV time rules on screen time [45]. Mixed evidence was found from two studies in examining setting TV program rules and screen time $[43,46]$. The study conducted in 2005 found children whose parents had TV program rules watched more TV [46], but the finding was not supported by another study in 2007 [43]. In addition, one study revealed that more family rules about TV viewing were associated with less screen time [48]. Coviewing TV with a child $[35,46]$ and having meals when TV is on $[34,43]$ were associated with increased screen time. In addition, one study [45] found that monitoring child screen time was not associated with screen time, but stimulating a child to be active was associated to less screen time.

In contrast to parenting practices, the review found that there was moderate evidence suggesting parental self-efficacy and parents' own TV time were associated with children's screen time. Nine studies with a mean quality score of 4.8 consistently revealed that parents' own TV time was positively associated with their child's screen time [33-35, 37$40,42,44]$. The evidence was also consistent in four studies (a mean quality score of 5.5), which concluded that high parental self-efficacy in reducing children's screen time was associated with less screen time in children [36-38, 47].

In terms of associations of parental perceptions and parenting style with screen time, the evidence was weak and inconsistent from only four studies reviewed. For example, two studies revealed that parental perception of their child spending too much time on playing video games or watching TV was associated with increased screen time $[33,38]$. Parental perception of "TV helps" was found to be associated with increased screen time [37, 43]. Parental perception of "TV hurts" was associated with decreased screen time [46]. But this association was not supported by another study conducted by the same author [43]. 
The authoritative parenting style was found to be associated with decreased children's screen time by only one study [41].

\section{Discussion}

By critically assessing and synthesizing evidence from individual studies, the present systematic review updates the current literature and fills knowledge gaps in relation to associations of parental influences with young children's PA and screen viewing behaviours. Moderate to strong evidence was found in relation to the associations of parental encouragement/support for PA and parents' own PA level with children's PA. Moderate evidence was also found regarding associations of parental self-efficacy and parents' own screen time with children's screen time. Associations of other aspects of parenting practices, parental perceptions, and parenting style with children's PA and screen time were indeterminate due to limited studies and contradictory results from studies included in this review.

4.1. What Is Already Known? Three previous systematic reviews summarised mixed evidence of associations of parents' PA and parental encouragement/support with children's PA $[10,12,16]$. Hinkley et al. and Mitchell et al. concluded that parents' PA was positively associated with young children's PA $[12,16]$, while de Craemer et al. found indeterminate association [10]. Likewise, Mitchell et al. found that there was positive association between parental encouragement/support and children's PA [16], yet Hinkley et al. and de Craemer et al. found no such association $[10,12]$. Another systematic review that included several qualitative studies suggested that parent involvement, encouragement, and modelling of PA may be important influences impacting young children's PA and are worthy of further systematic study [50].

Of four previous systematic reviews of association between parents' TV time and children's screen time, two concluded a positive association $[9,11]$, while the other two found that there was a positive but indeterminate association $[10,13]$. Mixed findings about the association between parental TV rules and children's screen time were reported by three reviews $[9,10,13]$. Cillero and Jago and Hinkley et al. found that children with TV rules had less screen time $[9,13]$, while de Craemer et al. found that this association was indeterminate [10].

Mixed evidence in relation to associations of parental influences with children's PA and screen time was further explored by some qualitative studies. For example, Dwyer et al. found that that parental modelling and/or encouragement of activity was a key influence and predictor of PA and sedentary behaviour in children, which was especially acknowledged by parents [51]. Another qualitative study found parents' own screen viewing habits was one of the two most frequently mentioned factors that influence children's screen time (the other one was weather conditions) [52]. Parents also liked the idea of implementing parental rules for $\mathrm{TV}$ viewing (e.g., time rules, no TV viewing during meals) [52].
4.2. What This Study Adds. The present review examines the evidence of associations of parental influences with both PA and screen time of young children. Findings from the review generally support and reinforce the evidence found in some of the previous reviews. This review also examined the role of parental rules for PA and screen viewing, parent perceptions of children's PA, and screen viewing and found their effects on children's PA and screen time remained indeterminate because of contradictive findings or a small number of studies.

Unlike previous reviews that only focused on parenting practices, the present review also explores parental selfefficacy and general parenting style as part of the parental influences. Moderate evidence was found that increased parental self-efficacy was associated with reduced children's screen time. But, the effect of parental self-efficacy on increasing children's PA cannot be concluded with only one study found in this review. The association of parenting style with children's PA and screen time remains unclear due to the limited number of studies.

4.3. Evidence Gaps and Future Research. Despite substantial evidence suggesting that an authoritative parenting style was associated with older children's PA and sedentary behaviours $[53,54]$, the present systematic review was not able to make such conclusion for young children with only one study included in the review [31, 41]. Therefore, the associations of parenting style and young children's PA and sedentary behaviours need more attention in future research. In this review, only one longitudinal study found that the relationship between parent's PA and preschool children's PA was stronger than that in older children (at follow-up) [32]. It seems likely that the associations of various parental influences and children's PA and screen viewing behaviours would change with advancing age of children. Hence, further longitudinal research on parental influences is needed. In addition, there is a clear evidence gap regarding the effect of parental self-efficacy on children's PA.

As discussed above, associations of some parenting practices (e.g., setting PA and TV rules) and parental perceptions with children's PA and screen time are still indeterminate and further investigation is needed to inform the development of health promotion programs. Inconsistent findings of the association between setting TV rules and children's screen time could be a result of different levels of obedience of rules. One qualitative study involving six European countries revealed that, in general, parents of preschoolschool children only had informal rules about TV viewing [52]. In this review, two individual studies were conducted by Vandewater et al. in United States in 2005 and 2007 $[43,46]$. The first study found that parental perceptions of "TV hurts" and setting TV time rules were associated with decreased screen time [46]. However, such associations were not found in a later study [43]. It may be that the association between parental perception of "TV hurts" and children's screen time was related to setting TV time rules. Thus, more research is needed to investigate whether the parental perception of TV "hurts" influences establishing and 
enforcing TV rules. In addition, whether parenting practices are moderated by general parenting style also needs to be investigated.

\section{Conclusions}

In the early years of life, some parental influences were significantly associated with young children's PA and screen time with moderate to strong evidence. Results from the present review suggest that parents' encouragement and support can increase their children's PA and reducing parents own screen time can lead to decreased child screen time. Improving parenting practices, parental self-efficacy and parenting style may also be promising approaches to increasing PA time and decreasing screen time of young children.

\section{Strengths and Limitations of This Review}

One of the strengths of this review is that we used comprehensive and systematic inclusion and exclusion criteria and a modified quality assessment tool for the critical appraisals of papers. With this quality assessment tool, the strength of evidence from individual study could be assessed based on a quality assessment score. In the present review, the concept of parental influences included not only parents' role modelling and parenting practices that were commonly included in previous reviews, but also general parenting style, parental self-efficacy, and parental perception of PA and screen time, which are important aspects of parenting. In addition, this review searched six databases which enable a wider range of studies to be found.

However, due to the heterogeneity of studies included in the review we were not able to conduct a meta-analysis. Evidence derived from this review was limited by various measurements used regarding parents' and children's PA as well as aspects of parental influences. The definition of children's screen time was inconsistent in the papers reviewed. Study sample sizes in these papers reviewed noticeably varied from 69 to 10,694 where small sample size undermines the study findings. In addition, most studies were crosssectional which means it is difficult to make causal inference. Therefore, consideration must be given when interpreting the results.

\section{Conflict of Interests}

The authors declared no conflict of interests with respect to the research, authorship, and/or publication of this paper.

\section{References}

[1] B. A. Dennison, T. A. Erb, and P. L. Jenkins, “Television viewing and television in bedroom associated with overweight risk among low-income preschool children," Pediatrics, vol. 109, no. 6, pp. 1028-1035, 2002.

[2] R. Jago, T. Baranowski, J. C. Baranowski, D. Thompson, and K. A. Greaves, "BMI from 3-6y of age is predicted by TV viewing and physical activity, not diet," International Journal of Obesity, vol. 29 , no. 6 , pp. 557-564, 2005.
[3] M. M. van Stralen, S. J. te Velde, F. van Nassau et al., "Weight status of European preschool children and associations with family demographics and energy balance-related behaviours: a pooled analysis of six European studies," Obesity Reviews, vol. 13, supplement 1, pp. 29-41, 2012.

[4] L. H. Epstein, J. N. Roemmich, J. L. Robinson et al., "A randomized trial of the effects of reducing television viewing and computer use on body mass index in young children," Archives of Pediatrics and Adolescent Medicine, vol. 162, no. 3, pp. 239-245, 2008.

[5] M. L. Fitzgibbon, M. R. Stolley, L. Schiffer, L. Van Horn, K. Kauferchristoffel, and A. Dyer, "Two-year follow-up results for Hip-Hop to Health Jr.: a randomized controlled trial for overweight prevention in preschool minority children," Journal of Pediatrics, vol. 146, no. 5, pp. 618-625, 2005.

[6] J. Kain, R. Uauy, Albala, F. Vio, R. Cerda, and B. Leyton, "School-based obesity prevention in Chilean primary school children: methodology and evaluation of a controlled study," International Journal of Obesity, vol. 28, no. 4, pp. 483-493, 2004.

[7] J. F. Sallis, T. L. McKenzie, T. L. Conway et al., "Environmental interventions for eating and physical activity: a randomized controlled trial in middle schools," American Journal of Preventive Medicine, vol. 24, no. 3, pp. 209-217, 2003.

[8] K. Rhee, "Childhood overweight and the relationship between parent behaviors, parenting style, and family functioning," Annals of the American Academy of Political and Social Science, vol. 615, no. 1, pp. 12-37, 2008.

[9] I. H. Cillero and R. Jago, "Systematic review of correlates of screen-viewing among young children," Preventive Medicine, vol. 51, no. 1, pp. 3-10, 2010.

[10] M. de Craemer, E. de Decker, I. de Bourdeaudhuij et al., "Correlates of energy balance-related behaviours in preschool children: a systematic review," Obesity Reviews, vol. 13, no. 1, pp. 13-28, 2012.

[11] H. Duch, E. M. Fisher, I. Ensari, and A. Harrington, "Screen time use in children under 3 years old: a systematic review of correlates," International Journal of Behavioral Nutrition and Physical Activity, vol. 10, article 102, 2013.

[12] T. Hinkley, D. Crawford, J. Salmon, A. D. Okely, and K. Hesketh, "Preschool children and physical activity: a review of correlates," The American Journal of Preventive Medicine, vol. 34, no. 5, pp. 435-441, 2008.

[13] T. Hinkley, J. Salmon, A. D. Okely, and S. G. Trost, "Correlates of sedentary behaviours in preschool children: a review," International Journal of Behavioral Nutrition and Physical Activity, vol. 7, article 66, 2010.

[14] J. F. Sallis, J. J. Prochaska, and W. C. Taylor, "A review of correlates of physical activity of children and adolescents," Medicine and Science in Sports and Exercise, vol. 32, no. 5, pp. 963-975, 2000.

[15] F. de Montigny and C. Lacharité, "Perceived parental efficacy: concept analysis," Journal of Advanced Nursing, vol. 49, no. 4, pp. 387-396, 2005.

[16] J. Mitchell, H. Skouteris, M. McCabe et al., "Physical activity in young children: a systematic review of parental influences," Early Child Development and Care, vol. 182, no. 11, pp. 1411-1437, 2012.

[17] D. R. Lubans, C. A. Boreham, P. Kelly, and C. E. Foster, "The relationship between active travel to school and health-related 
fitness in children and adolescents: a systematic review," International Journal of Behavioral Nutrition and Physical Activity, vol. 8, article 5, 2011.

[18] E. von Elm, D. G. Altman, M. Egger, S. J. Pocock, P. C. Gøtzsche, and J. P. Vandenbroucke, "Strengthening the reporting of observational studies in epidemiology (STROBE) statement: guidelines for reporting observational studies," British Medical Journal, vol. 335, no. 7624, pp. 806-808, 2007.

[19] B. L. Alderman, T. B. Benham-Deal, and J. M. Jenkins, "Change in parental influence on children's physical activity over time," Journal of Physical Activity and Health, vol. 7, no. 1, pp. 60-67, 2010.

[20] M. Oliver, G. M. Schofield, and P. J. Schluter, "Parent influences on preschoolers' objectively assessed physical activity," Journal of Science and Medicine in Sport, vol. 13, no. 4, pp. 403-409, 2010.

[21] P. D. Loprinzi and S. G. Trost, "Parental influences on physical activity behavior in preschool children," Preventive Medicine, vol. 50, no. 3, pp. 129-133, 2010.

[22] K. A. Pfeiffer, M. Dowda, K. L. McIver, and R. R. Pate, "Factors related to objectively measured physical activity in preschool children," Pediatric Exercise Science, vol. 21, no. 2, pp. 196-208, 2009.

[23] C. A. Zecevic, L. Tremblay, T. Lovsin, and L. Michel, "Parental influence on young children's physical activity," International Journal of Pediatrics, vol. 2010, Article ID 468526, 9 pages, 2010.

[24] K. K. Davison and L. L. Birch, "Child and parent characteristics as predictors of change in girls' body mass index," International Journal of Obesity, vol. 25, no. 12, pp. 1834-1842, 2001.

[25] R. Jago, T. Baranowski, D. Thompson, J. Baranowski, and K. A. Greaves, "Sedentary behavior, not TV viewing, predicts physical activity among 3- to 7-year-old children," Pediatric Exercise Science, vol. 17, no. 4, pp. 364-376, 2005.

[26] M. W. Beets and J. T. Foley, "Association of father involvement and neighborhood quality with kindergartners' physical activity: a multilevel structural equation model," The American Journal of Health Promotion, vol. 22, no. 3, pp. 195-203, 2008.

[27] V. Cleland, A. Timperio, J. Salmon, C. Hume, L. A. Baur, and D. Crawford, "Predictors of time spent outdoors among children: 5-year longitudinal findings," Journal of Epidemiology and Community Health, vol. 64, no. 5, pp. 400-406, 2010.

[28] M. Dowda, K. A. Pfeiffer, W. H. Brown, J. A. Mitchell, W. Byun, and R. R. Pate, "Parental and environmental correlates of physical activity of children attending preschool," Archives of Pediatrics and Adolescent Medicine, vol. 165, no. 10, pp. 939-944, 2011.

[29] T. Hinkley, J. Salmon, A. D. Okely, K. Hesketh, and D. Crawford, "Correlates of preschool children's physical activity," The American Journal of Preventive Medicine, vol. 43, no. 2, pp. 159-167, 2012.

[30] R. Ruiz, S. B. Gesell, M. S. Buchowski, W. Lambert, and S. L. Barkin, "The relationship between hispanic parents and their preschool-aged children's physical activity," Pediatrics, vol. 127, no. 5, pp. 888-895, 2011.

[31] D. P. Schary, B. J. Cardinal, and P. D. Loprinzi, "Parental support exceeds parenting style for promoting active play in preschool children," Early Child Development and Care, vol. 182, no. 8, pp. 1057-1069, 2012.

[32] R. W. Taylor, L. Murdoch, P. Carter, D. F. Gerrard, S. M. Williams, and B. J. Taylor, "Longitudinal study of physical activity and inactivity in preschoolers: the flame study," Medicine \& Science in Sports \& Exercise, vol. 41, no. 1, pp. 96-102, 2009.
[33] D. J. Barr-Anderson, J. A. Fulkerson, M. Smyth et al., "Associations of American Indian children's screen-time behavior with parental television behavior, parental perceptions of children's screen time, andmedia-related resources in the home," Preventing Chronic Disease, vol. 8, no. 5, article A105, 2011.

[34] C. S. Birken, J. Maguire, M. Mekky et al., "Parental factors associated with screen time in pre-school children in primarycare practice: a TARGet Kids! study," Public Health Nutrition, vol. 14, no. 12, pp. 2134-2138, 2011.

[35] A. Bleakley, A. B. Jordan, and M. Hennessy, "The relationship between parents' and children's television viewing," Pediatrics, vol. 132, no. 2, pp. e364-e371, 2013.

[36] K. Campbell, K. Hesketh, A. Silverii, and G. Abbott, "Maternal self-efficacy regarding children's eating and sedentary behaviours in the early years: associations with children's food intake and sedentary behaviours," International Journal of Pediatric Obesity, vol. 5, no. 6, pp. 501-508, 2010.

[37] V. Carson and I. Janssen, "Associations between factors within the home setting and screen time among children aged 05years: a cross-sectional study," BMC Public Health, vol. 12, no. 1, article 539, 2012.

[38] T. Hinkley, J. Salmon, A. D. Okely, and D. Crawford, "The correlates of preschoolers' compliance with screen recommendations exist across multiple domains," Preventive Medicine, vol. 57, no. 3, pp. 212-219, 2013.

[39] G. Kourlaba, K. Kondaki, T. Liarigkovinos, and Y. Manios, "Factors associated with television viewing time in toddlers and preschoolers in Greece: the GENESIS study," Journal of Public Health, vol. 31, no. 2, pp. 222-230, 2009.

[40] V. L. Rideout, E. A. Vandewater, and E. A. Wartella, "The media family: electronic media in the lives of infants toddlers preschoolers and their parents," http://www.dcmp.org/caai/ nadh169.pdf.

[41] D. P. Schary, B. J. Cardinal, and P. D. Loprinzi, "Parenting style associated with sedentary behaviour in preschool children," Early Child Development and Care, vol. 182, no. 8, pp. 1015-1026, 2012.

[42] A. L. Thompson, L. S. Adair, and M. E. Bentley, "Maternal characteristics and perception of temperament associated with infant tv exposure," Pediatrics, vol. 131, no. 2, pp. e390-e397, 2013.

[43] E. A. Vandewater, V. J. Rideout, E. A. Wartella, X. Huang, J. H. Lee, and M.-S. Shim, "Digital childhood: electronic media and technology use among infants, toddlers, and preschoolers," Pediatrics, vol. 119, no. 5, pp. e1006-e1015, 2007.

[44] S. S. Yalçin, B. TuĞrul, N. Naçar, M. Tuncer, and K. Yurdakök, "Factors that affect television viewing time in preschool and primary schoolchildren," Pediatrics International, vol. 44, no. 6 , pp. 622-627, 2002.

[45] J. S. Gubbels, S. P. J. Kremers, A. Stafleu et al., "Association between parenting practices and children's dietary intake, activity behavior and development of body mass index: the KOALA birth cohort study," International Journal of Behavioral Nutrition and Physical Activity, vol. 8, article 18, 2011.

[46] E. A. Vandewater, S.-E. Park, X. Huang, and E. A. Wartella, "“'No-you can't watch that": parental rules and young children's media use," American Behavioral Scientist, vol. 48, no. 5, pp. 608-623, 2005.

[47] B. J. Smith, A. Grunseit, L. L. Hardy, L. King, L. Wolfenden, and A. Milat, "Parental influences on child physical activity and screen viewing time: a population based study," BMC Public Health, vol. 10, article 593, 2010. 
[48] N. J. Spurrier, A. A. Magarey, R. Golley, F. Curnow, and M. G. Sawyer, "Relationships between the home environment and physical activity and dietary patterns of preschool children: a cross-sectional study," International Journal of Behavioral Nutrition and Physical Activity, vol. 5, article 31, 2008.

[49] E. E. Maccoby and J. A. Martin, "Socialization in the context of the family: parent-child interaction," in Handbook of Child Psychology: Socialization, Personality, and Social Development, P. H. Mussen and E. M. Hetherington, Eds., pp. 1-101, Wiley, New York, NY, USA, 4th edition, 1983.

[50] L. Emma and M. Jarrett, "How we play-cultural determinants of physical activity in young children," 2010, http://www .playscotland.org/wp-content/uploads/assets/HowWePlayLitReview.pdf.

[51] G. M. Dwyer, J. Higgs, L. L. Hardy, and L. A. Baur, "What do parents and preschool staff tell us about young children's physical activity: a qualitative study," International Journal of Behavioral Nutrition and Physical Activity, vol. 5, no. 66, 2008.

[52] E. De Decker, M. De Craemer, I. De Bourdeaudhuij et al., "Influencing factors of screen time in preschool children: an exploration of parents' perceptions through focus groups in six European countries," Obesity Reviews, vol. 13, no. 1, pp. 75-84, 2012.

[53] J. M. Berge, "A review of familial correlates of child and adolescent obesity: what has the 21st century taught us so far?" International Journal of Adolescent Medicine and Health, vol. 21, no. 4, pp. 457-483, 2009.

[54] A. Lohaus, M. Vierhaus, and J. Ball, "Parenting styles and health-related behavior in childhood and early adolescence: results of a longitudinal study," The Journal of Early Adolescence, vol. 29, no. 4, pp. 449-475, 2009. 


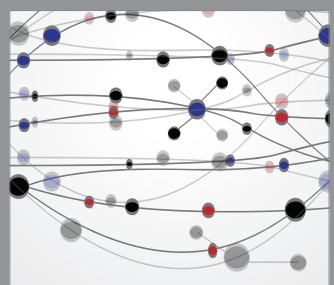

The Scientific World Journal
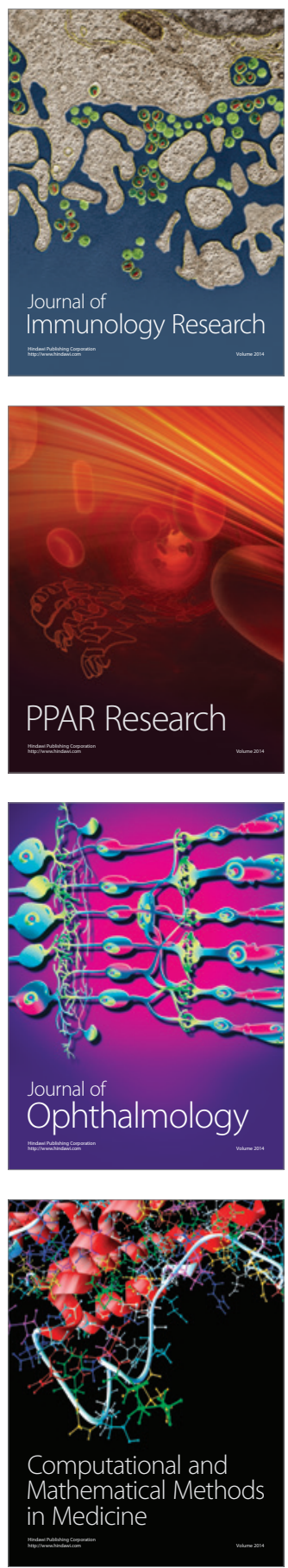

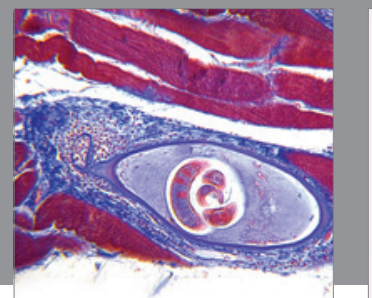

Gastroenterology

Research and Practice
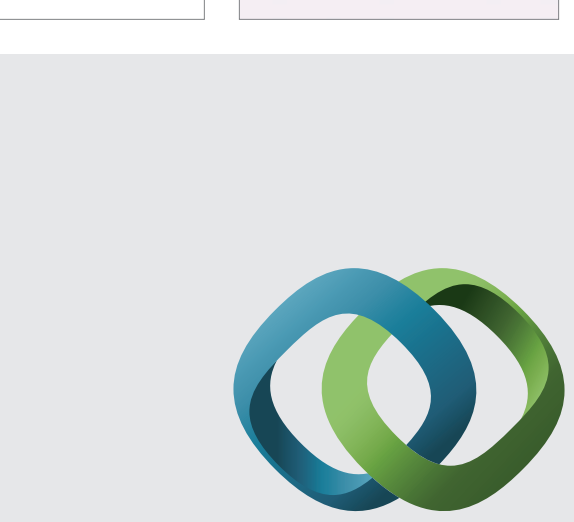

\section{Hindawi}

Submit your manuscripts at

http://www.hindawi.com
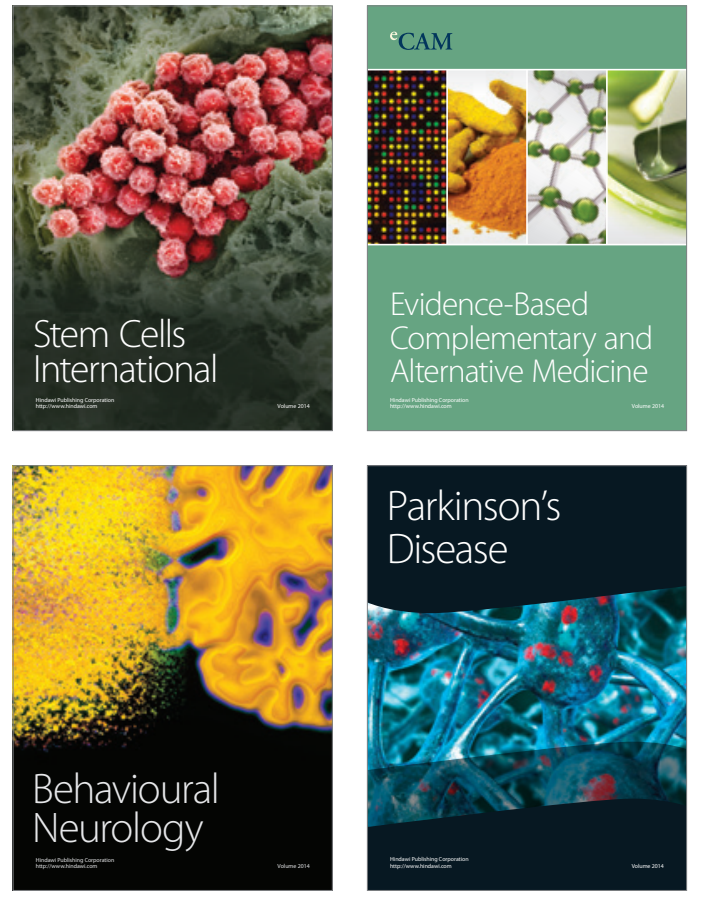
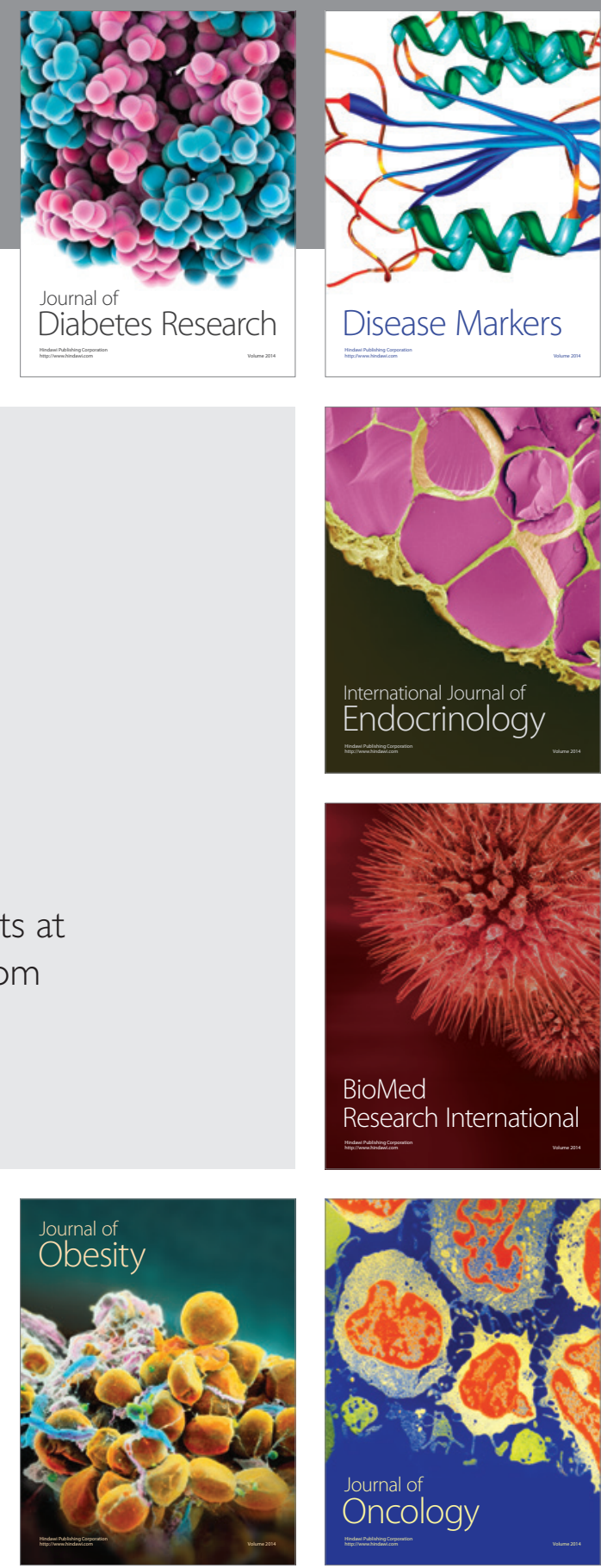

Disease Markers
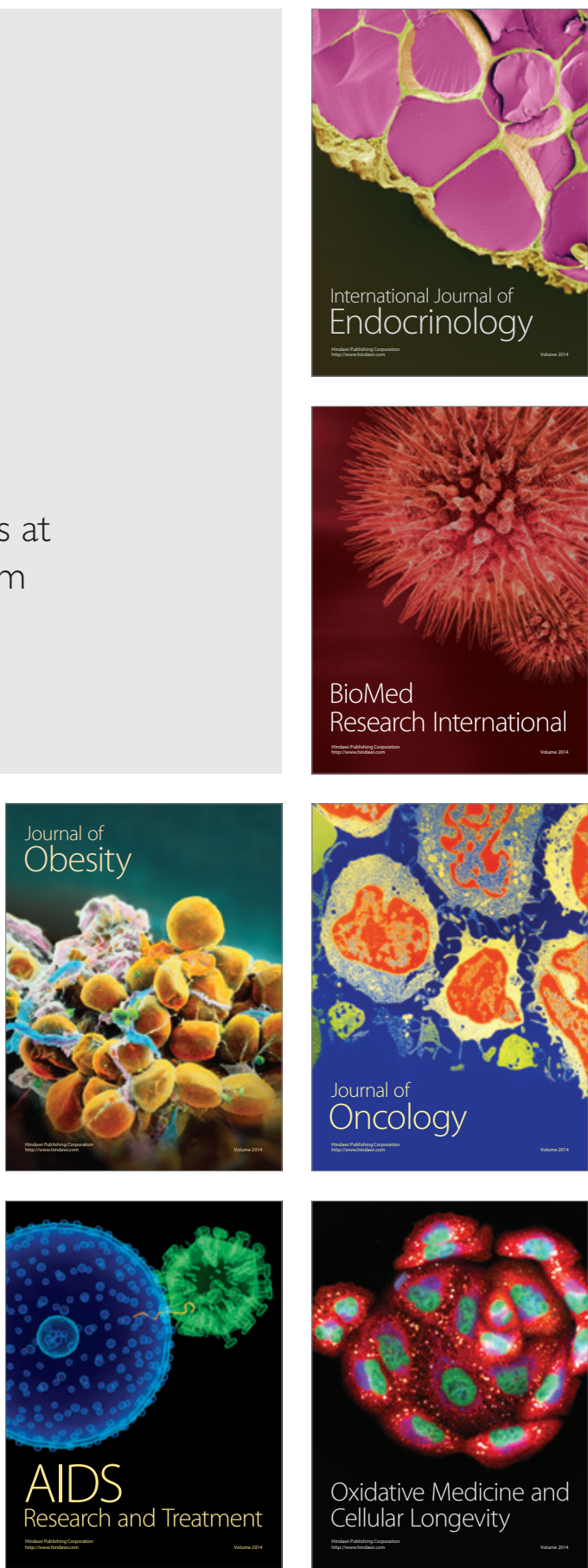